\title{
Sporozoite neutralizing antibodies elicited in mice and rhesus macaques immunized with a Plasmodium falciparum repeat peptide conjugated to meningococcal outer membrane protein complex
}

\author{
Craig Przysiecki ${ }^{1}$, Bob Lucas ${ }^{1}$, Robert Mitchell ${ }^{2}$, Daniel Carapau ${ }^{2+}$, Zhiyun Wen ${ }^{1}$, Hui Xu ${ }^{1}$, \\ Xin-Min Wang ${ }^{1}$, Debbie Nahas ${ }^{1}$, Chengwei Wu ${ }^{1}$, Robert Hepler ${ }^{1}$, Elizabeth Ottinger ${ }^{3}$, \\ Jan ter Meulen ${ }^{1}$, David Kaslow ${ }^{4 \dagger}$, John Shiver ${ }^{1}$ and Elizabeth Nardin ${ }^{2 *}$ \\ Vaccines Research, Merck Research Laboratories, West Point, PA, USA \\ 2 Division of Medical Parasitology, Department of Microbiology, New York University School of Medicine, New York, NY, USA \\ ${ }^{3}$ National Center for Advancing Translational Sciences (NCATS), National Institutes of Health, Bethesda, MD, USA \\ ${ }^{4}$ Research Medicine, Merck Research Laboratories, Upper Gwynedd, PA, USA
}

\section{Edited by:}

Lisa A. Morici, Tulane University

School of Medicine, USA

\section{Reviewed by:}

Kai Matuschewski, Max Planck

Institute for Infection

Biology, Germany

Ahmed Aly, Tulane University, USA

*Correspondence:

Elizabeth Nardin, Division of

Medical Parasitology, Department of

Microbiology, New York University

School of Medicine, 341 East 25th

Street, New York, NY 10010, USA.

e-mail: elizabeth.nardin@nyumc.org

${ }^{\dagger}$ Present address:

Daniel Carapau, Instituto de

Medicina Molecular Malaria Unit,

Edifício Egas Moniz, Piso 3,

1649-028 Lisboa, Portugal.

David Kaslow, Path Malaria Vaccine

Initiative, 455 Massachusetts

Avenue NW, Suite 1000

Washington, DC 20001, USA.
Antibodies that neutralize infectivity of malaria sporozoites target the central repeat region of the circumsporozoite (CS) protein, which in Plasmodium falciparum is comprised primarily of 30-40 tandem NANP tetramer repeats. We evaluated immunogenicity of an alum-adsorbed (NANP) 6 peptide conjugated to an outer membrane protein complex (OMPC) derived from Neisseria meningitidis, a carrier protein used in a licensed Haemophilus influenzae pediatric vaccine. Mice immunized with (NANP) ${ }_{6}-\mathrm{OMPC}$ adsorbed to Merck's alum adjuvant (MAA), with or without Iscomatrix ${ }^{\circledR}$ as co-adjuvant, developed high levels of anti-repeat peptide antibody that inhibited in vitro invasion of human hepatoma cells by transgenic $P$. berghei sporozoites that express $P$. falciparum CS repeats (PfPb). Inhibition of sporozoite invasion in vitro correlated with in vivo resistance to challenge by the bites of PfPb-infected mosquitoes. Challenged mice had $>90 \%$ reduction of hepatic stage parasites as measured by real-time PCR, and either sterile immunity, i.e., no detectable blood stage parasites, or delayed prepatent periods which indicate neutralization of a majority, but not all, sporozoites. Rhesus macaques immunized with two doses of (NANP) ${ }_{6}-\mathrm{OMPC} / \mathrm{MAA}$ formulated with Iscomatrix ${ }^{\circledR}$ developed anti-repeat antibodies that persisted for $\sim 2$ years. A third dose of $(N A N P)_{6}-O M P C / M A A+$ Iscomatrix ${ }^{\circledR}$ at that time elicited strong anamnestic antibody responses. Rhesus macaque immune sera obtained post second and third dose of vaccine displayed high levels of sporozoite neutralizing activity in vitro that correlated with presence of high anti-repeat antibody titers. These preclinical studies in mice of different MHC haplotypes and a non-human primate support use of CS peptide-OMPC conjugates as a highly immunogenic platform to evaluate CS protective epitopes. Potential pre-erythrocytic vaccines can be combined with sexual blood stage vaccines as a multi-antigen malaria vaccine to block invasion and transmission of Plasmodium parasites.

Keywords: $P$. falciparum, vaccine, sporozoites, peptide-OMPC, mice, rhesus, antibody

\section{INTRODUCTION}

Malaria caused by the parasite Plasmodium falciparum is considered one of the most prevalent and deadliest of diseases. The complexity of the Plasmodium life cycle, which involves multiple parasite stages in the mosquito vector and in the mammalian host, necessitates a multipronged control effort, ideally involving a combination of chemotherapy, vector control, and vaccines. Despite the fact that $40 \%$ of the world's population is at risk of malaria, with $300-500$ million cases and 1 million deaths each year, there is no licensed malaria vaccine available.
One of the lead vaccine candidates in clinical trials is the circumsporozoite (CS) protein which is a major surface protein of the infective sporozoite. A Phase III trial is in progress of a CS-based pediatric malaria vaccine RTS,S which can protect $35-40 \%$ of African infants against clinical disease (Agnandji et al., 2011). Immunization with RTS,S in a potent adjuvant formulation elicited sterile immunity in $30-40 \%$ of malaria-naïve volunteers, however, only transient protection against infection was obtained in African adults (Bojang et al., 2001; Kester et al., 2009). Protection correlated with high levels of anti-repeat antibodies and CS-specific CD4+ T cells (Kester et al., 2009; Olotu 
et al., 2010, 2011). While these studies support the feasibility of a CS-based subunit vaccine, efforts continue to increase immunogenicity and efficacy of malaria vaccines using new adjuvant and delivery platforms.

The first trial of a malaria peptide vaccine directly targeting the CS repeats was the peptide-conjugate vaccine using tetanus toxoid (TT) as carrier protein, (NANP) $)_{3}$-TT, which elicited anti-repeat antibodies that protected a small number of immunized volunteers challenged by exposure to the bites of $P$. falciparum-infected mosquitoes (Herrington et al., 1987). These studies provided proof-of-principle that a CS repeat peptide vaccine could elicit protective immunity in humans, however, the magnitude of antirepeat antibody responses in this first clinical trial were suboptimal. The humoral response was dose dependent and a major limitation of the vaccine was the low density of peptide that could be conjugated to the TT carrier. The outer membrane protein complex (OMPC) of Neisseria meningitidis is an attractive carrier protein as it provides high density peptide conjugation. OMPC has a clinical track record as a carrier for polysaccharides in a pediatric Haemophilis influenzae type b (Hib) vaccine, PedvaxHIB $^{\circledR}$ (Merck), used safely in millions of infants worldwide (Zhou et al., 2002). The use of a carrier with prior applications in commercial pediatric vaccines would be particularly attractive for a malaria vaccine, as infants suffer the majority of the one million malaria deaths in Africa, and scale-up production, safety, and acceptability have been previously established. In previous studies, we have shown that a conjugate of OMPC to a $P$. falciparum gamete/ookinete protein, Pfs25, elicited high titers of transmission blocking antibodies in mice and rhesus macaques that reduced mosquito infection (Wu et al., 2006).

In the initial assessment of OMPC as carrier for $P$. falciparum CS repeats, synthetic peptide containing variable numbers of the $P$. falciparum NANP tetramer were conjugated to OMPC and tested with various adjuvants for immunogenicity in mice and rhesus macaques. In inbred strains of mice, (NANP) 6- $^{-}$ OMPC/Merck alum adjuvant (MAA) immunization elicited high levels of anti-repeat antibodies that neutralized sporozoite infectivity in vitro and in vivo. In rhesus macaques, (NANP) ${ }_{6}$ OMPC/MAA formulated with Iscomatrix ${ }^{\circledR}$ elicited anti-repeat antibodies that persisted for two years following a prime and boost immunization and strong anamnestic antibody responses were obtained following a second boost. The sporozoite neutralizing activity in the rhesus macaque sera correlated with levels of anti-repeat antibodies and neutralizing activity could be inhibited by presence of repeat peptide in a peptide competition assay. These promising studies in inbred and outbred animals support efforts to develop OMPC conjugates containing multiple malaria antigens to elicit immune responses that effectively block transmission of the parasite to the mammalian host as well as to the mosquito vector.

\section{MATERIALS AND METHODS SYNTHETIC PEPTIDES}

The $P$. falciparum CS repeat tetramers, $(\mathrm{NANP})_{3}$ and (NANP) $)_{6}$, were synthesized as bromoacetylated peptides with the latter peptide also synthesized having the bromoacetyl group at the C-terminus. A spacer 6-aminohexanoic acid (Aha) was incorporated between the repeats and BrAc. The nonbromoacetylated containing terminus of the peptide was blocked with an $\mathrm{N}$-acetyl or carboxamide group to give final constructs:

BrAcAha(NANP) ${ }_{3} \mathrm{NH}_{2}$ : BrAc-Aha-NANPNANPNANP-NH $\mathrm{NH}_{2}$ BrAcAha(NANP) ${ }_{6} \mathrm{NH}_{2}$ : BrAc-Aha-NANPNANPNANPNAN PNANPNANP-NH 2

Ac(NANP) ${ }_{6}$ LysAhaBrAc-NH $\mathrm{N}_{2}$ : Ac-NANPNANPNANPNANP NANPNANP-Lys (Aha-BrAc)- $\mathrm{NH}_{2}$

Peptides were cleaved from the resin with a mixture of $95 \%$ TFA, $2.5 \%$ water, and $2.5 \%$ triisopropylsilane. The crude peptide product was lyophilized to dryness, re-suspended in 50\% acetic acid and water (v:v), and purified by preparative RP-HPLC. Fractions were analyzed by LC/MS HPLC. Fractions with correct mass and $>95 \%$ homogeneity by peak area were pooled and lyophilized to dryness.

\section{CONJUGATION OF CS REPEAT PEPTIDES TO OMPC}

OMPC was obtained from Merck Manufacturing Division (West Point, PA). A portion of OMPC surface amines were aseptically thiolated using $\mathrm{N}$-acetylhomocysteinethiolactone (Aldrich, St. Louis, MO.) in $\mathrm{N}_{2}$-sparged borate buffered saline $(25 \mathrm{mM}$ sodium borate, $\mathrm{pH} 8.5,0.15 \mathrm{M} \mathrm{NaCl}$ ), as previously described (Wu et al., 2006), with the final thiolated OMPC re-suspended in $\mathrm{N}_{2}$-sparged $25 \mathrm{mM}$ sodium borate, $\mathrm{pH} 8.5,0.15 \mathrm{M} \mathrm{NaCl}$. Free thiol content was determined by Ellman assay and measured thiol content was between 0.2 and $0.3 \mu \mathrm{mol} / \mathrm{mL}$. Peptides were resuspended in $\mathrm{N}_{2}$-sparged borate buffered saline $(25 \mathrm{mM}$ borate, $0.15 \mathrm{M}$ sodium chloride, $\mathrm{pH} 8.5$ ) at $5 \mathrm{mg} / \mathrm{mL}$ and $0.22 \mu \mathrm{m}$ filtered. Peptides were mixed with the thiolated OMPC solution at a final 1.5-fold molar excess of peptide BrAc to total OMPC thiol. The reaction was protected from light and incubated at ambient temperature for $\sim 22 \mathrm{~h}$. Residual free OMPC thiol groups were quenched with a 5-fold molar excess of $\mathrm{N}$-ethylmaleimide for $4 \mathrm{~h}$ at ambient temperature. Quenched conjugates were dialyzed exhaustively against borate buffered saline dialysis buffer in Spectra-Por 100,000 Da MWCO dialysis units (Spectrum Labs, Rancho Dominguez, CA). Any aggregated material in the dialyzed product was removed by centrifugation at $2,280 \times \mathrm{g}$ for $5 \mathrm{~min}$ at $4^{\circ} \mathrm{C}$.

\section{CONJUGATE ANALYSIS}

Total protein content was determined by a modified Lowry assay (Markwell et al., 1978) and aliquots of conjugate and control OMPC (thiol activated OMPC, N-ethylmalemide quenched, and dialyzed) were analyzed by quantitative amino acid analysis (AAA). Peptide to OMPC molar ratios were determined from quantitation of the unique residue $\mathrm{S}$ carboxymethylhomocysteine (SCMHC) which was released upon acid hydrolysis of the nascent peptide-OMPC bond (Nahas et al., 2008). The OMPC-specific concentration was determined from hydrolysis-stable residues which were absent from the peptide sequence and thus unique to OMPC protein. Assuming $1 \mathrm{~mol}$ of peptide for every mol SCMHC, the ratio of SCMHC/OMPC was thus equivalent to the peptide/OMPC content. The mass loading of peptide could be calculated from this ratio using the peptide molecular weight and an average OMPC mass of 40,000,000 Da. 
The covalent nature of the conjugation was qualitatively confirmed by SDS-PAGE analysis using 4-12\% Bis-Tris NuPAGE gels (Invitrogen, Carlsbad, CA) where an upward shift in mobility was observed for the Coomassie-stained conjugate bands relative to control activated and quenched OMPC (data not shown).

\section{ADJUVANT FORMULATION}

Conjugates were adsorbed to Merck's amorphous aluminum hydroxyphosphate sulfate adjuvant (MAA) (Merck Manufacturing Division, West Point, PA) to give a final aluminum concentration of $0.45 \mathrm{mg} / \mathrm{ml}$. The $\mathrm{Al}^{3+} /$ dose were $0.045 \mathrm{mg}$ for mice and $0.225 \mathrm{mg}$ for rhesus macaques. In some experiments, a saponin-based adjuvant, Iscomatrix ${ }^{\circledR}$ (CSL, Melbourne, VIC, Australia), was added to the MAA-adsorbed peptide conjugate to give a final concentration of $0.025 \mathrm{mg}$ Isco units/mL for mouse preparation $(2.5 \mu \mathrm{g} /$ dose $)$ and $0.1 \mathrm{mg}$ Isco units $/ \mathrm{mL}$ for the rhesus macaque preparation $(50 \mathrm{mcg} / \mathrm{dose})$.

\section{MURINE IMMUNOGENICITY STUDIES}

All murine studies were approved by IACUC at New York University School of Medicine and Merck Research Laboratories (West Point, PA). Female Balb/c mice (Taconic Farms) or C57Bl/6 mice (Jackson Labs, Me), 6-8 weeks of age ( $n=5-10$ /group) were given three $4 \mu \mathrm{g}$ doses of conjugated peptide on days 0 , 14 , and 28 by hind leg intramuscular (IM) injection. Three constructs were tested that differed in number of repeats and peptide orientations: conjugation to $\mathrm{N}$-terminus of $(\mathrm{NANP})_{3}$ or $(\mathrm{NANP})_{6}$ peptide [OMPC-Aha(NANP) ${ }_{3} \mathrm{NH}_{2} / \mathrm{MAA}$ and OMPCAha $(\mathrm{NANP})_{6} / \mathrm{MAA}$, respectively], and $\mathrm{C}$-terminal conjugation of $(\mathrm{NANP})_{6}$-OMPC/MAA. The $(\mathrm{NANP})_{6}$-OMPC/MAA Cterminal conjugation was evaluated with and without the addition of Iscomatrix ${ }^{\circledR}$ as co-adjuvant. Control mice were immunized with activated/quenched but non-conjugated OMPC adsorbed to MAA. In an additional experiment, mice received two doses of OMPC/MAA prior to immunization with single dose of (NANP) 6 -OMPC/MAA. Blood samples were obtained for serum prior to each immunization and at various time points post second dose to measure antibody persistence. Serum was stored at $-20^{\circ} \mathrm{C}$ until assayed.

\section{RHESUS MACAOUES IMMUNOGENICITY STUDIES}

Adult Macaca mulatta rhesus macaques of Indian origin, 6 years of age at the start of the study, were housed at an AAALAC approved facility at New Iberia Research Center (NIRC), New Iberia, LA. Rhesus macaque studies were approved by IACUC at NIRC and Merck Research Laboratories. Groups of three adult rhesus macaques were given three $4 \mu \mathrm{g}$ doses of (NANP) $6^{-}$ OMPC/MAA on days 0,70 , and 732 by deltoid IM injection. The MAA adsorbed peptide conjugate was tested with and without Iscomatrix ${ }^{\circledR}$ as co-adjuvant. Blood was drawn intravenously at days $1,35,69,84,140,200,300,365,732$, and 760. Sera was generated from the blood samples using serum separators and stored at $-70^{\circ} \mathrm{C}$.

\section{SEROLOGIC ASSAYS}

Enzyme-linked immunoadsorbent assay (ELISA) was carried out to measure anti-repeat antibodies using as coating antigen either (NANP) 3 tetrabranched peptide (Nardin et al., 1995) or $\mathrm{R} 32$, an E. coli expressed recombinant protein containing 32 tetramer repeats (Young et al., 1985). Briefly, 96-well plates (Nunc Immuno Plate, MaxiSorp or Immunolon $2 \mathrm{HB}$ ) were coated with $100 \mathrm{ng} /$ well of recombinant R32 protein or with $1 \mu \mathrm{g} / \mathrm{ml}$ tetrabranched $(\mathrm{NANP})_{3}$ peptide. Murine or rhesus macaque sera were tested at 2-fold dilutions starting at 1:80 dilution. MAB 2A10, specific for $P$. falciparum CS repeats, was titrated on each plate as a positive control. Plates were washed using PBS with $0.05 \%$ Tween 20 prior to addition of species specific peroxidase-labeled anti-IgG antibody (Sigma-Aldrich, St. Louis, MO; or Kirkegaard, Perry Laboratories, Gaithersburg, MD). Plates were subsequently washed after incubation using PBS/0.05\% Tween20. Color development was accomplished using ABTS 1:1 (Fisher) and plates read at wavelength $\mathrm{A}_{405 \mathrm{~nm}}$. Antibody endpoints were determined based on a cut-off OD greater than three times OD in BSA-coated wells. The $\mathrm{ug} / \mathrm{ml}$ of anti-repeat antibody was determined by linear regression based on titration of MAB $2 \mathrm{~A} 10$.

Indirect immunofluorescence (IFA) was carried out using two-fold dilutions of pooled mouse sera, or individual rhesus macaques sera incubated on multiwell slides containing air-dried P. falciparum sporozoites (Othoro et al., 2009). Following washing, slides were reacted with species-specific FITC-labeled anti-Ig antibodies (Kirkegaard, Perry Laboratories; Gaithersburg, MD). Slides were coded and the endpoint titer was defined as the highest sera dilution giving sporozoites with unequivocal positive fluorescence.

The circumsporozoite precipitin (CSP) reaction is a terminal precipitin that forms on viable sporozoites incubated in immune serum due to antibody cross-linking of the surface CS protein (Vanderberg et al., 1969; Cochrane et al., 1976). CSP reactions were carried out using $\mathrm{PfPb}$ sporozoites, a transgenic $P$. berghei strain that expresses $P$. falciparum CS repeats (Persson et al., $2002)$. Equal volumes of sporozoites $\left(1 \times 10^{6} / \mathrm{ml}\right)$ and 2 -fold dilutions of immune sera were incubated for $45 \mathrm{~min}$ at $37^{\circ} \mathrm{C}$. The endpoint titer was defined as the last serum dilution giving $2+$ CSP reactions in a total of 20 sporozoites when examined by phase-contrast microscopy.

\section{TRANSGENIC SPOROZOITE NEUTRALIZATION ASSAY (TSNA)}

The presence of functional inhibitory antibodies was determined in vitro using $\mathrm{PfPb}$ sporozoites, transgenic P. berghei parasites expressing P. falciparum repeats (Kumar et al., 2004; Othoro et al., 2009). PfPb sporozoites $\left(2 \times 10^{4}\right)$ were incubated with serial dilutions of murine or rhesus macaque sera for $40 \mathrm{~min}$ on ice prior to addition to 24 well plates containing confluent HepG2 cells. Controls included sporozoites incubated with $25 \mu \mathrm{g} / \mathrm{ml}$ of MAB 2A10, specific for $P$. falciparum CS repeats or MAB 3D11 specific for $P$. berghei CS repeats, or with medium only. Plates were cultured for $48 \mathrm{~h}$ at $37^{\circ} \mathrm{C}$ and $5 \% \mathrm{CO}_{2}$, harvested and total RNA extracted and reverse transcribed. Parasite levels were quantitated by real-time qPCR using primers for parasite $18 \mathrm{~S}$ ribosomal RNA, as previously described (Bruna-Romero et al., 2001; Othoro et al., 2009).

\section{CHALLENGE BY EXPOSURE TO BITES OF PAPb-INFECTED MOSOUITOES}

Immunized and naïve $\mathrm{C} 57 \mathrm{Bl} / 6$ mice were anesthetized and challenged by exposure for $15 \mathrm{~min}$ to the bites of $10-20$ Anopheles stephansi mosquitoes infected with $\mathrm{PfPb}$ transgenic rodent parasites expressing the $P$. falciparum CS repeats. Forty 
hours post challenge, mice were sacrificed, livers removed, and RNA extracted for measurement of parasite burden by qPCR, as described for TSNA. The remaining mice where followed by microscopy using daily Giemsa-stained blood smears to determine presence of blood stage parasites. Mice that remained blood stage parasite negative for 14 days post challenge were considered to have sterile immunity.

\section{RESULTS}

\section{IMMUNOGENICITY OF (NANP) 6 -OMPC CONJUGATE IN INBRED STRAINS OF MICE}

Initial studies carried out in BALB/c mice established the number of repeats and peptide orientation required for optimal immunogenicity of the peptide-OMPC conjugates. A peptide-OMPC conjugate containing six NANP repeats, (NANP) 6 -OMPC, was found to elicit higher anti-repeat antibody titers than the conjugate containing three NANP repeats, (NANP) $)_{3}$-OMPC. Peptide orientation did not affect immunogenicity, as no difference was observed between $\mathrm{N}$ - or C-terminal conjugation of the (NANP) 6 peptide to OMPC (data not shown). All subsequent studies were therefore carried out using an (NANP) $)_{6}$-OMPC conjugate.

$\mathrm{Balb} / \mathrm{c}$ mice were immunized on days 0,14 , and 28 by IM injection of $4 \mu \mathrm{g}$ (NANP) ${ }_{6}$-OMPC (total peptide in conjugate) adsorbed to MAA (Merck amorphous aluminum hydroxphosphate sulfate), with or without Iscomatrix ${ }^{\circledR}$ as co-adjuvant. All conjugates were dosed based on the specific peptide content as measured by quantitative AAA. Following the third dose of (NANP) 6 -OMPC/MAA, peak anti-repeat antibody concentrations of $\sim 1,200 \mu \mathrm{g} / \mathrm{ml}$ were measured by ELISA (Figure 1). The magnitude of the antibody response was comparable using either $(\mathrm{NANP})_{3}$ peptide or recombinant $\mathrm{R} 32$ protein coated plates in the ELISA.

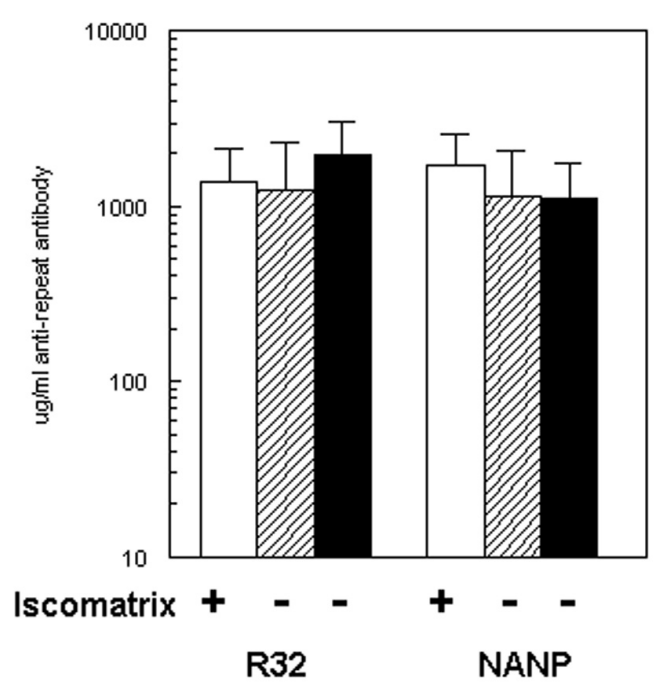

FIGURE 1 | Immunogenicity of (NANP) 6 -OMPC in BALB/c. Mice ( $n=10$ /group) were immunized with three doses of (NANP) $)_{6}$-OMPC/MAA with (open bars) or without (hatched bars) Iscomatrix®. ELISA used either recombinant protein $\mathrm{R} 32$ (left panel), or (NANP) 3 peptide (right panel). Antibody levels obtained with freshly prepared (NANP) 6 -OMPC/MAA (hatched bars) were compared with peptide-conjugate stored for 2 years at $4^{\circ} \mathrm{C}$ (black bars).
Addition of the Iscomatrix ${ }^{\circledR}$ co-adjuvant to the MAA formulation did not significantly increase immunogenicity (Figure 1, open bar). In the second experiment, $\mathrm{BALB} / \mathrm{c}$ mice gave comparable results when immunized with the same preparation of peptide conjugate which had been stored at $4^{\circ} \mathrm{C}$ for $\sim 2$ years (Figure 1, black bars). The $\mu \mathrm{g} / \mathrm{ml}$ of repeat specific antibody in Experiment I was 1,130 $\mu \mathrm{g} / \mathrm{ml}$ and in Experiment II 1,110 $\mu \mathrm{g} / \mathrm{ml}$, corresponded to geometric mean endpoint titers (GMT) of 359,480 and 551,090, respectively, when measured against $(\mathrm{NANP})_{3}$ peptide. All subsequent murine studies were carried out using the (NANP) 6 -OMPC/MAA formulation without Iscomatrix ${ }^{\circledR}$.

Humoral immune responses in a second inbred strain, $\mathrm{C} 57 \mathrm{Bl} / 6$, demonstrated that the high level of anti-repeat antibody induced by (NANP) 6 -OMPC/MAA was not strain dependent and was highly reproducible (Figure 2). In two independent experiments in $\mathrm{C} 57 \mathrm{Bl} / 6$ mice, $100 \%$ seroconversion was obtained following a single dose of (NANP) 6 -OMPC /MAA, with $17-21 \mu \mathrm{g} / \mathrm{ml}$ of anti-repeat antibody (black solid bars vs. black hatched bars), corresponding to 12,607 vs. 6,967 GMT when expressed as endpoint titers (gray solid bars vs. gray hatched bars). A booster injection on day 14 elicited a 6-12fold increase in the anti-repeat titers. Peak antibody responses were obtained following the third dose, with an additional 25 -fold increase to $502-516 \mu \mathrm{g} / \mathrm{ml}$ of anti-repeat antibody, corresponding to GMT 376,405 and 305,736 in Experiment 1 and 2, respectively. The antibodies elicited by (NANP) $)_{6}$-OMPC reacted with native CS on sporozoites. The sera from mice immunized with either fresh or stored peptide-conjugate reacted with air-dried $P$. falciparum sporozoites with $\sim 10^{4}$ IFA titers. The

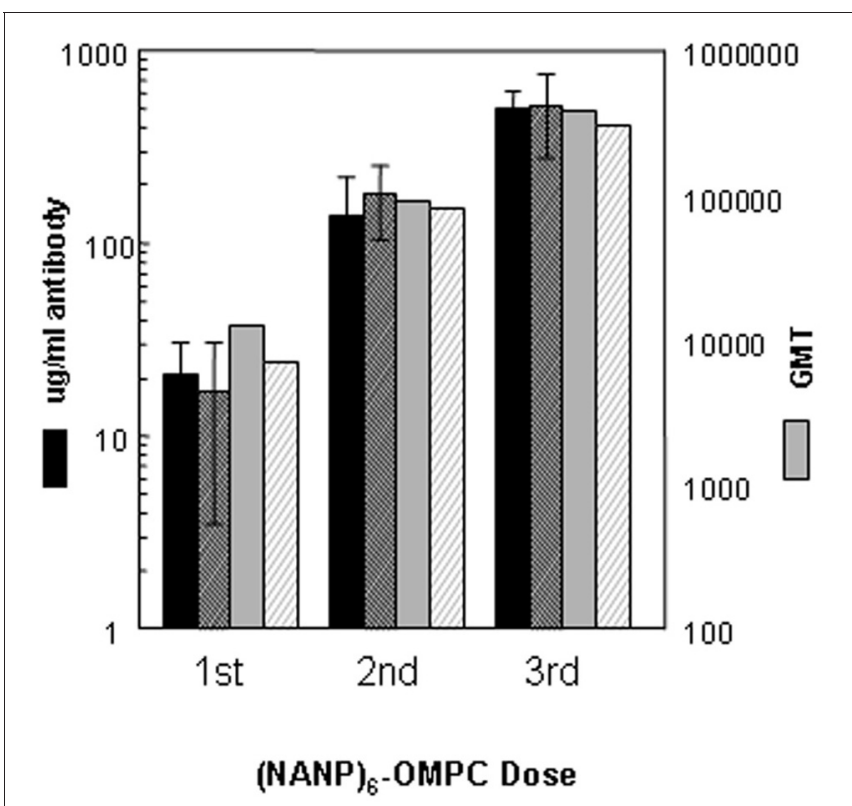

FIGURE 2 | Immunogenicity of (NANP) 6 -OMPC/MAA in C57BI/6 mice. Kinetics of anti-repeat antibody response shown for two experiments (solid bars Experiment I, hatched bars Experiment II). Antibody concentration is shown as $\mu \mathrm{g} / \mathrm{ml}$ (left axis) or geometric mean titers (GMT) (right axis), as measured in ELISA using either R32 (black bars) or (NANP) 3 peptide (gray bars) as coating antigen. 
immune sera also elicited high CSP titers (1:125) when incubated with viable $\mathrm{PfPb}$ sporozoites expressing $P$. falciparum CS repeats, indicating that the antibodies elicited by the peptide conjugates effectively cross-linked the surface CS protein on viable sporozoites.

OMPC is a carrier for bacterial capsular polysaccharide in a Haemophilus influenzae type b pediatric vaccine (PedvaxHIB ${ }^{\circledR}$ ), which is widely used to prevent childhood bacterial meningitis. Therefore, a proportion of infants might have antibody to the OMPC carrier that could positively or negatively modulate the response to (NANP) ${ }_{6}$-OMPC vaccine. To test whether anti-OMPC antibodies modulate the anti-repeat response, mice were primed with two doses of OMPC (anti-OMPC GMT 5,120) followed by a single dose of (NANP) ${ }_{6}$-OMPC/MAA.

The kinetics and magnitude of the anti-repeat antibody in OMPC-immunized mice were comparable to responses elicited when (NANP) 6 -OMPC was used to immunize mice without pre-existing anti-OMPC antibodies (Figure 3). The pre-existing anti-OMPC antibody also did not alter the persistence of the anti-repeat antibody response, with GMT of 761 and 905 at 160 days post the single dose of (NANP) ${ }_{6}$-OMPC/MAA in mice with or without pre-existing anti-OMPC antibodies, respectively. Importantly, the development of malaria-specific memory B cells was also not affected, as exposure to the bites of PfPb infected mosquitoes at day 160 increased anti-repeat antibody responses in both the OMPC-primed and non-primed mice. These findings suggest that the potential presence of anti-OMPC antibodies will not inhibit response to a malaria peptide-OMPC conjugate. In addition, the findings also suggest that the vaccine induced

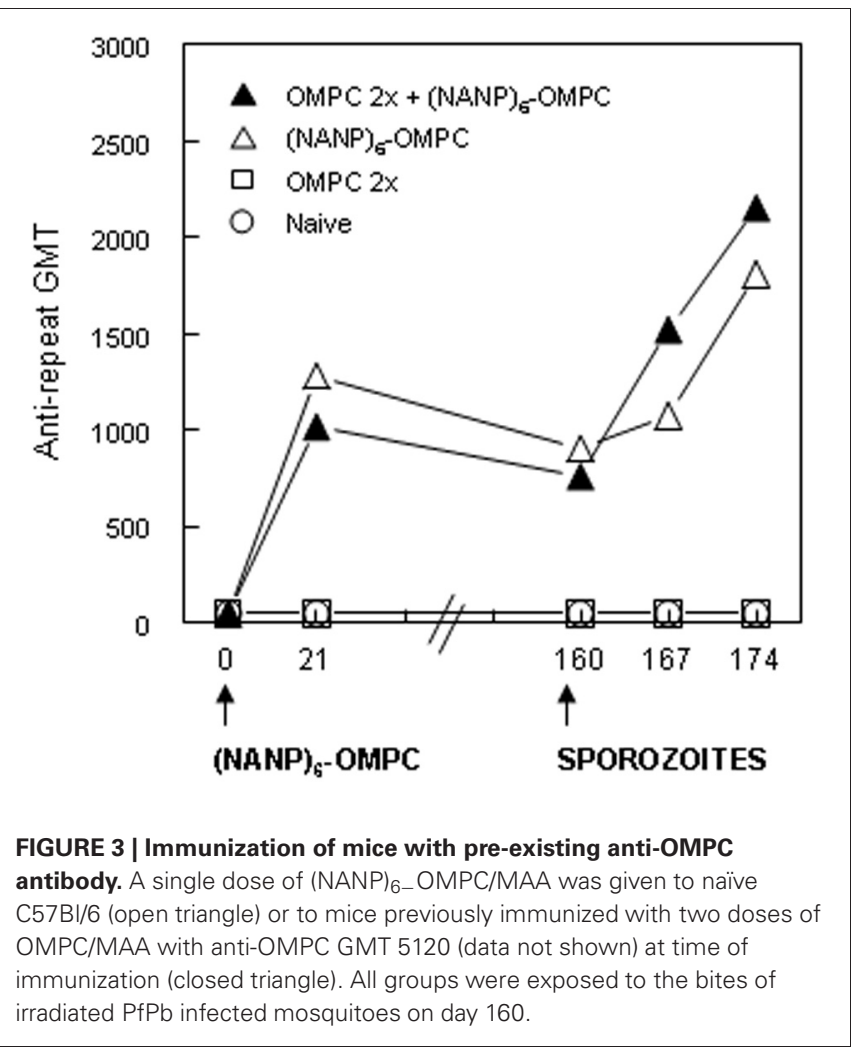

anti-repeat antibody response can be boosted by exposure to the bites of malaria-infected mosquitoes, providing the potential for continued boosters in malaria endemic areas.

\section{SPOROZOITE NEUTRALIZING ANTIBODY IN SERA OF (NANP) 6 -OMPC IMMUNIZED MICE}

The high titers of anti-repeat antibody elicited by immunization with (NANP) ${ }_{6}$-OMPC/MAA were found to be functional when tested in an in vitro sporozoite neutralizing assay using transgenic $P$. berghei sporozoites expressing $P$. falciparum CS repeats ( $\mathrm{PfPb}$ ) (Kumar et al., 2004). When PfPb sporozoites were preincubated with serum from (NANP) $)_{6}$ OMPC/MAA immunized $\mathrm{BALB} / \mathrm{c}$ mice prior to addition to HepG2 cell cultures, the number of intracellular parasites detected after $48 \mathrm{~h}$ culture was reduced by $\geq 90 \%$, when compared to cultures with sporozoites incubated in medium without antibody (Figure 4A). Similar levels of sporozoite neutralizing activity were detected in the serum of $\mathrm{C} 57 \mathrm{Bl} / 6$ mice immunized with (NANP) 6 -OMPC/MAA (Figure 4B). The level of inhibition observed with immune serum of BALB/c and $\mathrm{C} 57 \mathrm{Bl} / 6$ mice was comparable to that obtained when $\mathrm{PfPb}$ sporozoites were incubated with $25 \mu \mathrm{g} / \mathrm{ml}$ of MAB $2 \mathrm{~A} 10$ specific for $P$. falciparum CS repeats. Neutralizing activity was specific for $P$. falciparum CS repeats, as MAB 3D11 specific for P. berghei CS repeats did not inhibit $\mathrm{PfPb}$ sporozoite invasion. Control serum from mice immunized with OMPC/MAA only and serum of naïve mice were not inhibitory.

Inhibition was dose-dependent, and lower levels of parasite inhibition were detected at higher serum dilutions (Figure 4C). Sera of $8 / 10$ immunized C57Bl/6 mice gave $\geq 90 \%$ inhibition of liver stage parasites at a 1:10 dilution, while sera of 5/10 immune mice had neutralizing activity $>90 \%$ at 1:20 dilution. One of nine immune sera tested at 1:40 dilution gave $>90 \%$ inhibition. Control MAB 3D11 and serum of mice immunized with OMPC/MAA or naïve mice were not inhibitory at lowest dilution tested $(1: 10)$.

\section{SPOROZOITE NEUTRALIZING ANTIBODY In vivo}

To determine if sporozoite neutralization in vitro correlated with in vivo resistance to infection, the 10 (NANP) 6 -OMPC/MAA immunized mice, along with similar number of OMPC/MAA immunized control and naïve mice, were challenged by exposure to the bites of $\mathrm{PfPb}$-infected mosquitoes. Half of the mice were sacrificed at $40 \mathrm{~h}$ post challenge to measure parasite levels in the liver, while the other half were monitored for development of blood stage parasites using daily blood smears.

Reduction of $>90 \%$ of liver stage parasites relative to naïve mice was detected in 5/5 challenged mice when liver extracts were assayed by qPCR (Figure 5). In 4/5 of the (NANP) 6 -OMPC immunized mice, the number of rRNA copies was below the level of detection by qPCR ( $<10018 \mathrm{~S}$ rRNA copies). The parasite burden in the liver of mice immunized with OMPC only was lower than in naïve mice, suggesting potential non-specific innate immune responses were elicited by OMPC, which is a known TLR2 agonist (Latz et al., 2004) and/or the MAA adjuvant.

The in vitro sporozoite neutralization correlated with in vivo resistance to sporozoite challenge (Table 1). The remaining five immunized mice in the cohort challenged by bites of 
A

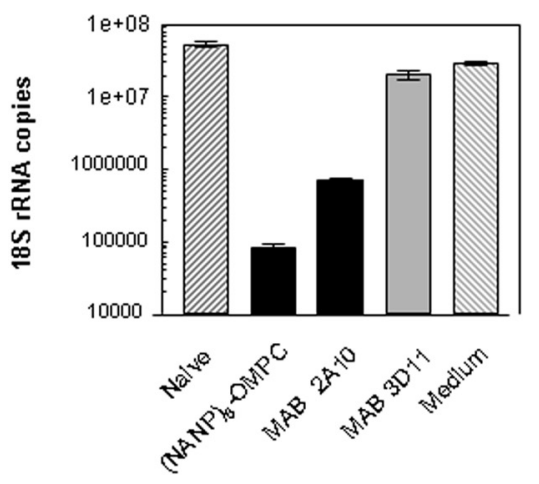

B

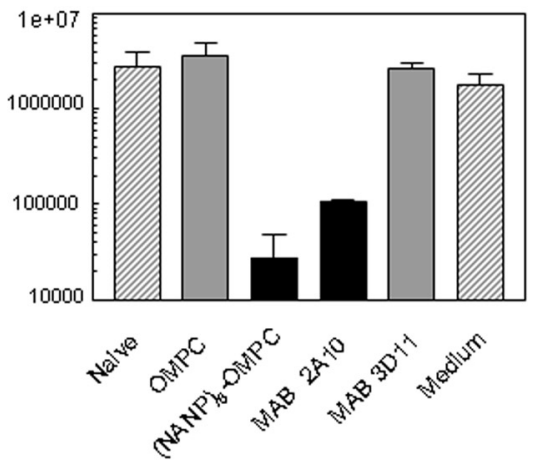

C

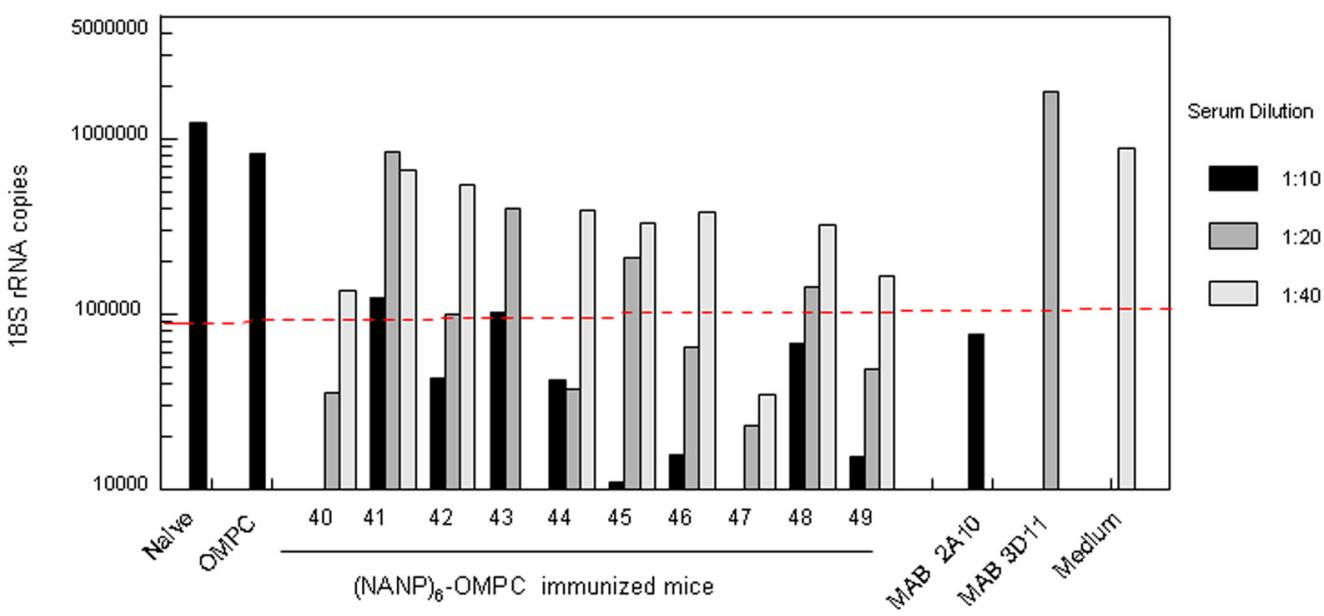

FIGURE 4 | Sporozoite meutralizing activity in murine immune serum. Sera from (A) Balb/c or (B) C57BI /6 mice immunized with three doses of

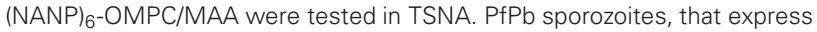
$P$. falciparum CS repeats, were incubated with immune or control sera (1:5 dilution) prior to addition to HepG2 cells. Levels of parasites in HepG2 cell extracts collected after $48 \mathrm{~h}$ of culture were measured by qPCR. Results are shown as mean number of parasite 18S rRNA copies in cell extracts, based on an 18S rRNA plasmid standard. (C) Individual sera of 10 C57BI/6 mice were tested in TSNA at dilutions of 1:10-1:40. Dotted line indicates $90 \%$ inhibition level.

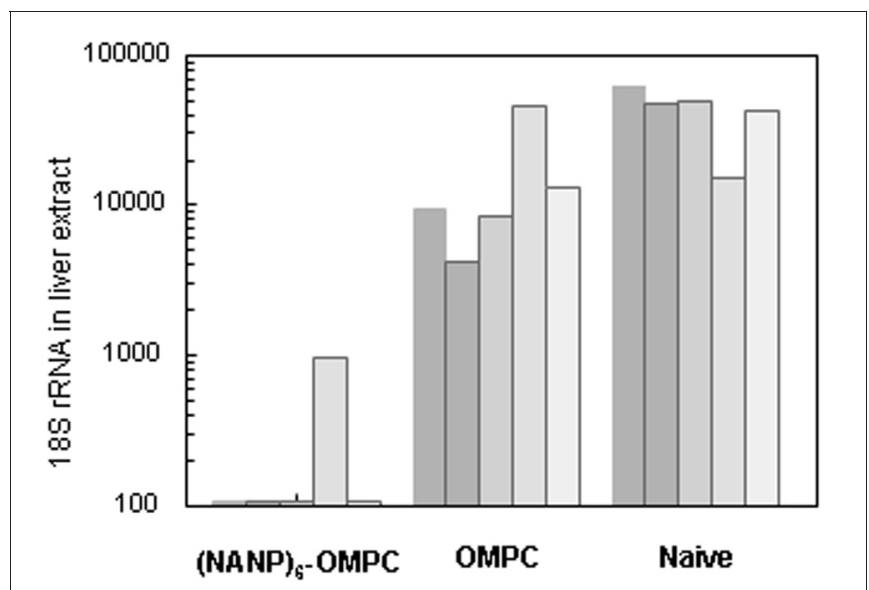

FIGURE 5 | Parasite levels in murine liver following challenge by bites of infected mosquitoes. Parasite $18 \mathrm{~S}$ rRNA copy numbers in liver extract obtained at $40 \mathrm{~h}$ post challenge by bites of 5-15 PfPb-infected mosquitoes was determined by qPCR. Results are shown for five mice in each group.
Table 1 | (NANP)6-OMPC immunized mice challenged by exposure to malaria-infected mosquitoes ${ }^{a}$.

\begin{tabular}{llllll}
\hline Experiment & Group & \# Pos/total & Protected\% & PPP $^{\boldsymbol{b}}$ & (Days) \\
\hline I & (NANP) $6-O M P C$ & $1+/ 5$ & 80 & 7.0 & - \\
& OMPC & $5+/ 5$ & 0 & 5.0 & $(4-6)$ \\
& Naive & $5+/ 5$ & 0 & 3.6 & $(3-4)$ \\
& (NANP) $6-O M P C$ & $3+/ 5$ & 40 & 6.7 & $(6-8)$ \\
& OMPC & $5+/ 5$ & 0 & 4.0 & $(3-5)$ \\
& Naive & $5+/ 5$ & 0 & 3.8 & $(3-4)$ \\
\hline
\end{tabular}

${ }^{a}$ Naïve or immunized C57BI/6 mice were challenged by exposure to bites of 18 mosquitoes infected with PfPb parasites expressing P. falciparum CS repeats.

${ }^{b}$ Prepatent period (PPP) is the first day blood stage parasites were detected by microscopy in Giemsa stained daily blood smears.

$\mathrm{PfPb}$-infected mosquitoes were monitored for development of parasitemia by microscopic examination of daily Giemsa-stained blood smears. No patent blood stage infection was detected in 4/5 immunized mice followed for 16 days post challenge, indicating 
sterile immunity was elicited by immunization with $(\mathrm{NANP})_{6}{ }^{-}$ OMPC. The single (NANP) ${ }_{6}$-OMPC immunized mouse that developed parasitemia had a delayed prepatent period of 7 days, which was significantly prolonged compared to the five naïve mice which all became patent 3-4 days post challenge. The sterile protection in these mice correlate with the low levels of parasite rRNA detected in liver at $48 \mathrm{~h}$ post challenge in the qPCR measurements carried out in the parallel cohort (Figure 5).

The development of protective immune responses in (NANP) $)_{6}$-OMPC immunized mice was confirmed in a second experiment, in which $2 / 5$ of (NANP $)_{6}$-OMPC immunized mice remained negative after sporozoite challenge (Table 1). The prepatent period in the immunized mice that developed blood stage infection was 6.7 days, vs. 4.0 days for OMPC immunized mice and 3.8 days for naive controls. The prolonged prepatent period in the (NANP) ${ }_{6}$-OMPC immunized mice that developed blood stage infection in Experiments 1 and 2, indicate that the majority, but not all, of the infective sporozoites injected by the mosquito were neutralized in vivo. Previous experiments using intravenous injection of know numbers of parasites have shown that elimination of $>90 \%$ of sporozoites is required to obtain a one day delay in developing a patent blood stage infection.

\section{IMMUNOGENICITY OF (NANP) 6 -OMPC CONJUGATES IN RHESUS MACAQUES}

The kinetics and fine specificity of antibody responses in an outbred non-human primate population, rhesus macaques, was assessed following IM immunization with (NANP) $6^{-}$ OMPC/MAA formulated with or without Iscomatrix ${ }^{\circledR}$ COadjuvant. In contrast to murine responses, the addition of Iscomatrix $^{\circledR}$ co-adjuvant was required for optimal antibody responses in the rhesus macaques (Figure 6). Three rhesus macaques injected with a single dose of (NANP) 6 -OMPC/ MAA + Iscomatrix ${ }^{\circledR}$ had GMT 65,020, while the three rhesus macaques immunized with (NANP) 6 -OMPC/MAA had a log

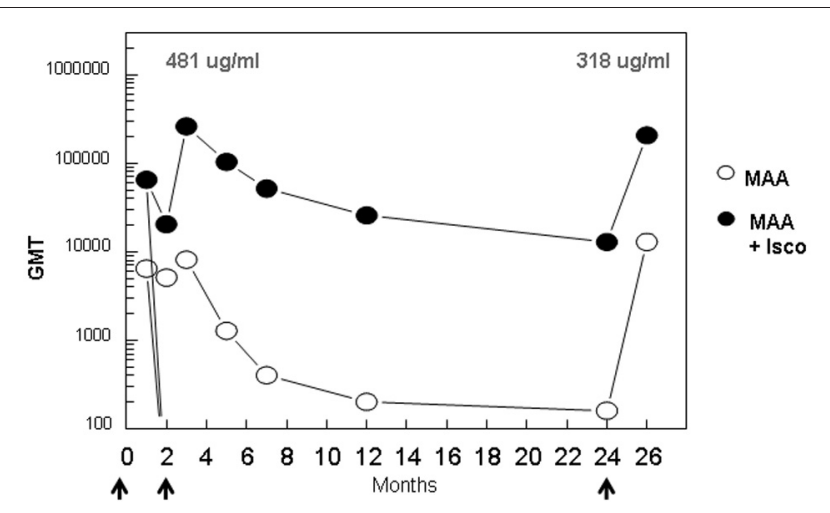

FIGURE 6 | Kinetics of anti-repeat antibody response in rhesus macaques. Groups of three adult rhesus macaques were immunized with (NANP) $_{6}$-OMPC/MAA with or without Iscomatrix ${ }^{\circledR}$ on days 0, 70, and 732 (arrows). Sera were collected at indicated time points and results are shown as ELISA GMT using (NANP) 3 peptide coated plates. The concentration of repeat specific antibody $(\mu \mathrm{g} / \mathrm{ml})$ is shown for peak responses post 1 st and 2 nd booster immunization. lower anti-repeat antibody GMT 6,451. A booster injection of $(\mathrm{NANP})_{6}$-OMPC/MAA + Iscomatrix ${ }^{\circledR}$ on day 70 , significantly increased anti-repeat antibody titers 4-fold to GMT 260,080 (corresponding to $481 \mu \mathrm{g} / \mathrm{ml}$ anti-repeat antibody). In marked contrast, in rhesus macaques immunized without Iscomatrix ${ }^{\circledR}$, the booster injection did not significantly increase antibody titer, with 8,127 GMT post boost as compared to 6,451 GMT post prime.

Persistence of high levels of anti-repeat antibody was also dependent on presence of Iscomatrix ${ }^{\circledR}$ co-adjuvant. Antirepeat antibody titers in macaques immunized with $(\mathrm{NANP})_{6}{ }^{-}$ OMPC/MAA + Iscomatrix ${ }^{\circledR}$ remained high for over 12 months, with a gradual decrease to GMT 25,803 at one year, as compared to GMT 202 in the absence of Iscomatrix ${ }^{\circledR}$. Reactivity with viable sporozoites expressing $P$. falciparum $C S$ repeats was also maintained in sera of rhesus macaques immunized with $(\mathrm{NANP})_{6}$-OMPC/MAA + Iscomatrix ${ }^{\circledR}$. CSP titers of $\geq 1: 512$ were obtained in pooled Day 84 sera, decreasing to $1: 32$ CSP titer on Day 365 (data not shown).

At $\sim 2$ years post immunization, rhesus macaques immunized with $(\mathrm{NANP})_{6}$-OMPC/MAA + Iscomatrix $^{\circledR}$ had GMT $12,902(19 \mu \mathrm{g} / \mathrm{mL}$ anti-repeat antibody). A second booster immunization with $(\mathrm{NANP})_{6}$-OMPC/MAA + Iscomatrix $^{\circledR}$ delivered at this time point elicited strong anamnestic antibody responses. At 1 month post the second boost, antibody levels in the (NANP) ${ }_{6}$-OMPC/MAA + Iscomatrix ${ }^{\circledR}$ immunized macaques reached GMT 206,425 (318 $\mu \mathrm{g} / \mathrm{ml}$ anti-repeat antibody), comparable to peak levels observed following first boost. In contrast, at 2 years only low levels were present in rhesus macaques immunized without Iscomatrix ${ }^{\circledR}$ (GMT 160). Following a boost with $(\mathrm{NANP})_{6}$-OMPC/MAA without Iscomatrix ${ }^{\circledR}$ at this time point, no anamnestic response was observed with antibody titers reaching levels observed post first dose, a log lower than levels in the macaques immunized with $(\mathrm{NANP})_{6}$-OMPC/MAA + Iscomatrix ${ }^{\circledR}$.

\section{SPOROZOITE NEUTRALIZING ANTIBODY in vitro}

The anti-repeat antibodies in the rhesus macaques immunized with $(\mathrm{NANP})_{6}$-OMPC/MAA + Iscomatrix $^{\circledR}$ were functional in vitro. Individual sera obtained post the 2nd dose (day 84) had high levels of anti-repeat antibodies in all three rhesus macaques, $\mathrm{Rh} 338, \mathrm{Rh} 340$, and $\mathrm{Rh} 342$ (Figure 7A, black bars). Corresponding with the presence of high levels of antirepeat antibodies, the immune sera of all three rhesus macaques had $>90 \%$ sporozoite neutralizing activity when tested at 1:5 dilution in the in vitro TSNA (Figure 7B, black bars).

Consistent with the $\sim 10$-fold decrease in anti-repeat antibodies at day 732, none of the rhesus macaques sera had sporozoite neutralizing activity $>90 \%$ at this time point (Figure 7A vs. 7B, hatched bars). Importantly, administration of a 2 nd booster of $(\mathrm{NANP})_{6}$-OMPC/MAA + Iscomatrix ${ }^{\circledR}$ on day 732 elicited a strong anamnestic antibody response in all three macaques. Serum obtained $\sim 1$ month post the second boost (day 760 ) had high levels of anti-repeat antibody that directly correlated with recovery of sporozoite neutralizing activity (Figure 7A vs. 7B, gray bars). The antibody titers and sporozoite neutralizing activity in day 760 sera was comparable to peak levels observed in day 84 sera following the first boost. 

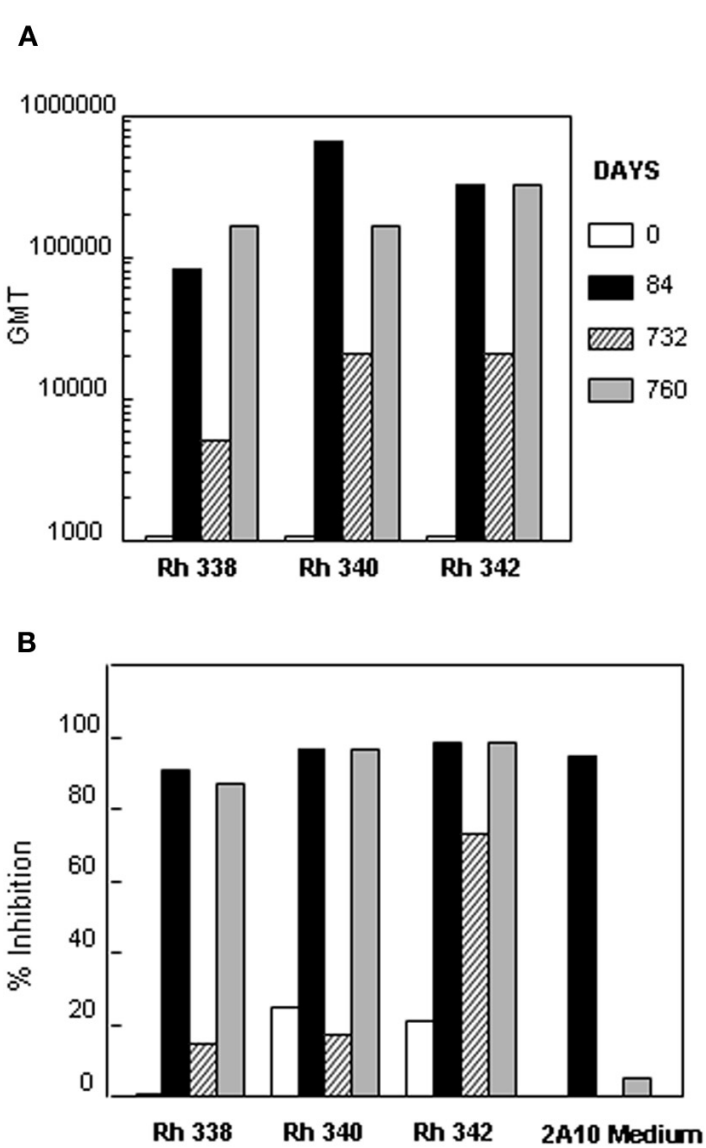

FIGURE 7 | Sporozoite neutralizing activity in immune sera of rhesus macaques. Sera was collected from three rhesus macaques at days 0 , 84, 732, and 760 post immunization with (NANP) 6 -OMPC/MAA + Iscomatrix $®$. (A) Sera were tested in ELISA with results shown as anti-repeat GMT. (B) TSNA was carried out using 1:5 serum dilution with results shown as mean \% Inhibition of PfPb sporozoite invasion of HepG2 cells.

Limitations on the number of rhesus macaques available precluded inclusion of an OMPC/MAA only group. In order to rule out non-specific inhibitory effects in the rhesus macaques serum, peptide competition TSNA were carried out to determine if sporozoite neutralizing activity was specific for $P$. falciparum CS repeats. Pre-incubation of rhesus macaques immune sera with various concentrations of $(\mathrm{NANP})_{3}$ repeat peptide was found to block sporozoite neutralizing activity in a dose dependent manner (Figure 8). In Rh 340, immune sera obtained +14 d post first boost (day 84 ) had 1:10 titer of sporozoite neutralizing activity in the absence of competitor peptide (open bar). Pre-incubation of the immune serum with $20 \mu \mathrm{g} / \mathrm{ml}$ (NANP) 3 competitor peptide reduced inhibition to levels observed in Day 0 serum (black bar). There was a dose-dependent increase in sporozoite neutralizing activity with lower concentrations of competitor peptide. Rh 340 immune serum incubated with $0.2 \mu \mathrm{g} / \mathrm{ml}$ of (NANP) 3 competitor peptide gave $>90 \%$ inhibition of sporozoite invasion of HepG2 cells, similar to sporozoite neutralizing activity in immune serum in the absence of competitor peptide.

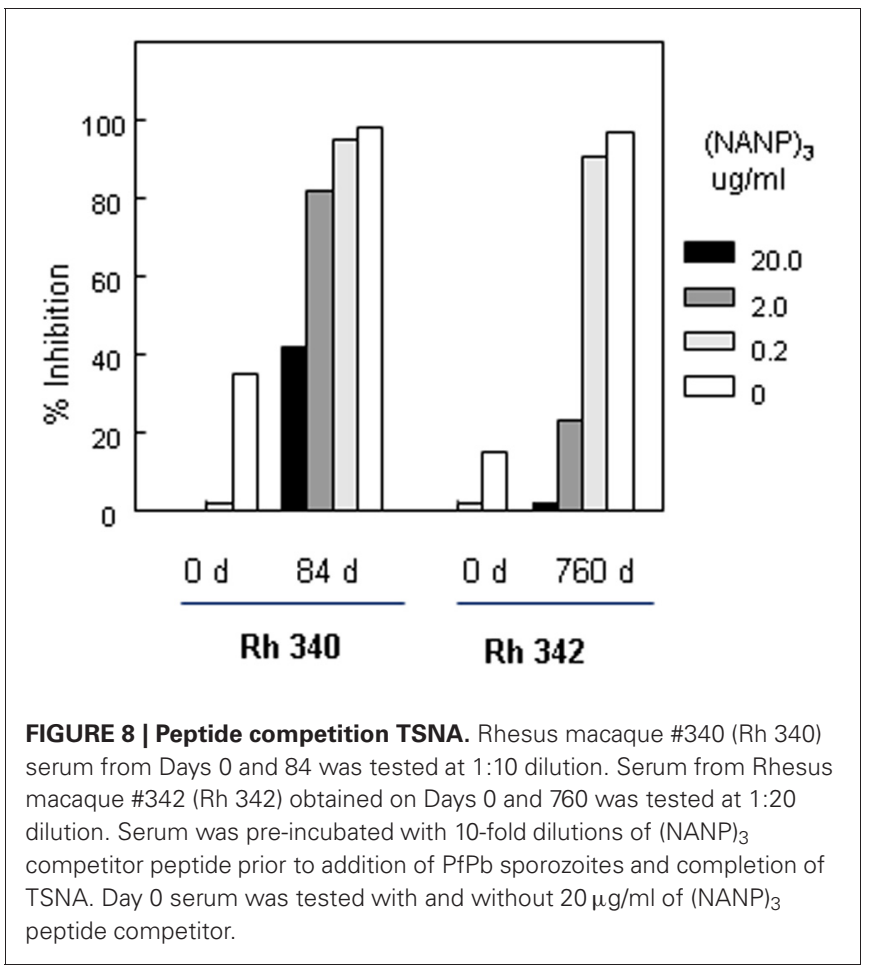

Similarly, Rh 342 immune serum obtained on Day 760, 1 month post the second boost with $(\mathrm{NANP})_{6}$-OMPC/MAA + Iscomatrix ${ }^{\circledR}$, had high levels of sporozoite neutralizing activity at 1:20 dilution in the absence of competitor peptide (open bar). Pre-incubation of Day 760 immune serum with either $20 \mu \mathrm{g} / \mathrm{ml}$ or $2 \mu \mathrm{g} / \mathrm{ml}$ of $(\mathrm{NANP})_{3}$ competitor peptide reduced inhibition to $5 \%$ and $20 \%$, similar to day 0 serum. At low doses of competitor peptide, $0.2 \mu \mathrm{g} / \mathrm{ml}$, sporozoite neutralizing activity was not blocked and percent inhibition was comparable to Day 760 immune serum without competitor peptide.

\section{DISCUSSION}

In the current study, the (NANP) 6 -OMPC conjugate adsorbed to MAA was found to be highly immunogenic in two inbred strains of mice, Balb/c and $\mathrm{C} 57 \mathrm{Bl} / 6$, and in out-bred rhesus macaques. The high levels of anti-repeat antibodies elicited in mice and rhesus macaques correlated with functional antibody that crosslinked surface CS protein in the CSP reaction and inhibited sporozoite invasion of hepatoma cells in vitro. These assays demonstrate the ability of antibodies elicited by (NANP) ${ }_{6}$-OMPC immunization to recognize CS repeats on the viable sporozoite and block motility required for invasion of host cells in vitro (Cochrane et al., 1976; Stewart et al., 1986).

Although the transgenic $P$. berghei parasites express $P$. falciparum CS repeats, they remain a rodent parasite biologically and thus allow comparison of inhibition in vitro with functional sporozoite neutralizing activity in vivo. (NANP) 6- $^{-}$ OMPC/MAA immunized mice with high levels of inhibitory antibodies in the in vitro assay, had significantly reduced parasite levels in the liver at $48 \mathrm{~h}$ post challenge exposure to the bites 
of $\mathrm{PfPb}$ infected mosquitoes. Moreover, the reduced parasite levels in the liver of immunized mice correlated with absence, or delayed, blood stage infection, as measured in Giemsa-stained blood smears. Partial protection in several of the challenged immunized mice was reflected in increased pre-patent periods, indicating that majority but not all infective sporozoites were neutralized.

Anti-repeat antibodies function in vivo by immobilizing sporozoites in the skin and preventing entrance into the blood circulation and transit to the liver and/or hindrance of CS interaction with host liver cells required for invasion (Cerami et al., 1992, 1994; Vanderberg and Frevert, 2004). Thus, a key goal of vaccine development is the identification of adjuvant and delivery systems to produce high levels of anti-repeat antibodies. While mice gave optimal responses with alum adsorbed peptide conjugate, Iscomatrix ${ }^{\circledR}$ was required as co-adjuvant for optimal antibody responses in non-human primates. Rhesus macaques immunized with (NANP) 6 -OMPC/MAA + Iscomatrix ${ }^{\circledR}$ had a log higher titer of anti-repeat antibodies compared to rhesus macaques immunized with (NANP) 6 -OMPC/MAA. The antibodies elicited by two doses of (NANP) ${ }_{6}$-OMPC/MAA + Iscomatrix ${ }^{\circledR}$ were longlived and could be detected for $\sim 2$ years post immunization. Encouragingly, a booster immunization at day 732 increased antibody to levels observed post 2 nd dose. In contrast, in the absence of Iscomatrix ${ }^{\circledR}$ co-adjuvant, the anti-repeat antibodies were logs lower in magnitude, did not give secondary responses and declined rapidly to near background levels. Similar strong adjuvant requirements were noted in rhesus macaques immunized with an influenza peptide conjugate, M2e-OMPC, formulated in MAA plus QS21, as compared to MAA only (Fan et al., 2004).

Consistent with the murine studies (Figure 4), the presence of high levels of anti-repeat antibody in rhesus macaques immunized with $(\mathrm{NANP})_{6}$-OMPC/MAA + Iscomatrix $^{\circledR}$ correlated with sporozoite neutralizing activity in the TSNA. All three rhesus macaques had neutralizing activity $>90 \%$ at $1: 5$ dilution in sera obtained post the first boost, and $2 / 3$ rhesus macaques had neutralizing titers of 1:20. The presence of sporozoite neutralizing activity in serum post the first boost (day 84) and second boost (day 760), directly correlated with the presence of high titers of anti-repeat antibody, with $481 \mu \mathrm{g} / \mathrm{ml}$ and $318 \mu \mathrm{g} / \mathrm{ml}$, respectively. Inhibition was specific for $P$. falciparum CS repeats, as preincubation of rhesus macaques immune serum with (NANP) 3 competitor peptide led to loss of sporozoite neutralizing activity in TSNA.

Recent clinical studies of CS subunit vaccines have found an association of high anti-repeat antibody titers and resistance to sporozoite challenge, although a threshold level of protective antibody has not been identified. In two recent Phase I/II trials of the CS-based RTS,S vaccine, immunized malarianaïve volunteers who developed sterile immunity following $P$. falciparum sporozoite challenge had significantly higher concentrations of anti-repeat antibody $(114-188 \mu \mathrm{g} / \mathrm{ml})$ and multifunctional CD4 $+\mathrm{T}$ cells when compared to non-protected individuals (30-73 $\mu \mathrm{g} / \mathrm{ml})$ (Kester et al., 2008, 2009). While direct comparison are difficult, the preclinical studies in mice and rhesus macaques of RTS,S in various adjuvant formulations gave levels of anti-repeat antibodies that were lower and less persistent than antibodies elicited by (NANP) ${ }_{6}$-OMPC/MAA \pm Iscomatrix ${ }^{\circledR}$. Mice immunized with RTS,S, in either the AS02 adjuvant (QS21, MPL in oil-in-water emulsion) or AS01 adjuvant (in which liposomes replace the oil-in-water component), developed peak anti-repeat antibody of $\sim 6 \times 10^{4}$ GMT in ELISA using the R32 recombinant protein as antigen (Mettens et al., 2008). In rhesus macaques, two doses of RTS,S, formulated in either the AS01 or AS02 adjuvant, elicited peak anti-repeat GMT $\sim 1.5 \times 10^{3}$, which decreased to near background by 8 weeks post boost. Following a second boost with RTS,S in either adjuvant, GMT rose to peak titers observed post the first boost, returning to near background at 22 weeks.

The current studies demonstrate that the magnitude and persistence of the anti-repeat response in mice and rhesus macaques immunized with two doses of (NANP) 6 -OMPC/MAA \pm Iscomatrix ${ }^{\circledR}$ was significantly higher $\left(1 \times 10^{5}\right)$ and more longlived ( $\sim 2$ years) than those observed following RTS,S immunization. The kinetics, magnitude, and persistence of anti-repeat antibodies in mice and rhesus macaques immunized with (NANP) $)_{6}$-OMPC are consistent with results of our previous studies with a $P$. falciparum Transmission Blocking Vaccine (TBV) (Wu et al., 2006). This vaccine, comprised of a recombinant sexual stage protein, Pfs25, conjugated to OMPC and adsorbed to MAA, elicited high levels of functional antibody in mice and rhesus macaques that inhibited oocyst formation in the mosquito midgut. Anti-Pfs 25 antibodies persisted for 18 months in rhesus macaques and could be boosted by injection of recombinant Pfs 25 protein. Following the second boost, the anamnestic antibody responses reached peak titers similar to those obtained after the first boost, as found also for anti-repeat antibodies in the $(\mathrm{NANP})_{6}-\mathrm{OMPC} / \mathrm{MAA}+$ Iscomatrix $^{\circledR}$ immunized rhesus macaques (Figure 6).

The enhanced immunogenicity of these malaria-OMPC conjugates may reflect unique OMPC interactions with the innate immune system. The vesicular structure of OMPC provides a particle with diameter 100-200 nm to enhance uptake by dendritic cells. OMPC is also a known TLR2 agonist, related to the presence in OMPC of porin proteins from the surface of N. meningitidis that has been shown to induce DC activation and maturation (Massari et al., 2002; Latz et al., 2004). In addition, the response to repeat peptide in human volunteers is known to be dose dependent and OMPC has a large capacity for peptide chemical conjugation, with $\sim 3,700 \mathrm{~mol} / \mathrm{mol}$ for $(\mathrm{NANP})_{6}-\mathrm{OMPC}$ as compared to the expected lower capacity for (NANP $)_{3}$-TT used in the first clinical trials of a synthetic peptide vaccine (Herrington et al., 1987). Adsorption of the peptide conjugates to alum adjuvant may further increase the immunogenicity of the OMPC based conjugates, by stimulating innate immune responses through NLRP3 inflammasome (Eisenbarth et al., 2008; Li et al., 2008). The combination of enhanced uptake by DC, innate immune signaling through TLR and/or inflammasome, and high density of the malaria epitope, may contribute to strong humoral responses in mice.

In contrast to mice, the $(\mathrm{NANP})_{6}$-OMPC/MAA formulation was not optimal for rhesus macaques. Induction of high levels of long-lived anti-repeat antibody in macaques required inclusion of a co-adjuvant, Iscomatrix ${ }^{\circledR}$. The $(\mathrm{NANP})_{6}$-OMPC/MAA+ Iscomatrix ${ }^{\circledR}$ formulation elicited titers 2 logs higher than the 
MAA only formulation, and these antibodies persisted for $\sim 2$ years. Iscomatrix ${ }^{\circledR}$ is a particulate adjuvant, comprised of cholesterol, phospholipid, and saponin, which has been shown to be safe in a series of clinical trials of cancer and viral vaccines (Sun et al., 2009; McKenzie et al., 2010). The requirement for stronger adjuvant formulation in rhesus macaques as compared to mice has been found in other studies. In general, a lower immunogenicity of malaria subunit vaccines has been observed in non-human primates. We have found that a stronger oil-based adjuvant was required for optimal immunogenicity of a CS viruslike particle (VLP) vaccine in rhesus macaques as compared to murine studies (Langermans et al., 2005). However, the formulation of VLP in stronger oil-in-water adjuvants was associated with unacceptable reactogenicity, with sterile abscesses developing in the immunized rhesus macaques. No reactogenicity was noted in rhesus macaques immunized with (NANP) ${ }_{6}$-OMPC/MAA + Iscomatrix ${ }^{\circledR}$ in the current studies.

The OMPC carrier has a strong safety record based on its use as carrier in an $H$. influenzae type b (Hib) pediatric vaccine, PedvaxHIB ${ }^{\circledR}$, which is comprised of $H$. influenzae capsular polysaccharide conjugated to OMPC and adsorbed to MAA. Hib vaccine has been delivered to millions of infants $2-71$ months old to prevent childhood bacterial meningitis. The well-established safety record of OMPC as carrier protein is particularly important, as the target population for a malaria vaccine is infants $<5$ years who suffer the majority of the mortality and morbidity caused by $P$. falciparum infection. While PedvaxHIB ${ }^{\circledR}$ vaccination can elicit anti-carrier antibodies that could potentially modulate immune responses to a (NANP) ${ }_{6}$-OMPC vaccine, we found comparable malaria-specific antibody responses induced in mice with and without pre-existing anti-OMPC antibodies. Moreover, the presence of pre-existing anti-OMPC antibodies did not inhibit

\section{REFERENCES}

Agnandji, S. T., Lell, B., Soulanoudjingar, S. S., Fernandes, J. F., Abossolo, B. P., Conzelmann, C., et al. (2011). First results of phase 3 trial of RTS, S/AS01 malaria vaccine in African children. N. Engl. J. Med. 365, 1863-1875.

Bojang, K. A., Milligan, P. J., Pinder, M., Vigneron, L., Alloueche, A., Kester, K. E., et al. (2001). Efficacy of RTS, S/AS02 malaria vaccine against Plasmodium falciparum infection in semi-immune adult men in The Gambia: a randomised trial. Lancet 358, 1927-1934.

Bruna-Romero, O., Hafalla, J. C., Gonzalez-Aseguinolaza, G., Sano, G., Tsuji, M., and Zavala, F. (2001). Detection of malaria liver-stages in mice infected through the bite of a single Anopheles mosquito using a highly sensitive real-time PCR. Int. J. Parasitol. 31, 1499-1502.

Cerami, C., Frevert, U., Sinnis, P., Takacs, B., Clavijo, P., Santos, M. J., et al. (1992). The basolateral domain of the hepatocyte plasma

sporozoite elicited anamnestic anti-repeat antibody responses in (NANP) $)_{6}$-OMPC immunized mice, suggesting that parasitespecific memory B cells were also not affected. These studies also suggest that antibody responses induced by (NANP) ${ }_{6}$-OMPC immunization can potentially be boosted by natural exposure to malaria infected mosquitoes in endemic areas.

The studies in mice and rhesus macaques demonstrate that OMPC conjugated to a large malaria recombinant protein $(\mathrm{Pfs} 25 \mathrm{H}, \mathrm{MW} 20 \mathrm{kDa}$ ) as well as a low molecular weight (NANP) peptide can elicit high levels of long-lived functional antibodies that inhibit parasite development in vitro and in vivo. The combination of both Pfs 25 and (NANP) ${ }_{6}$-OMPC conjugates in a vaccine could prevent transmission of parasites both to the mammalian host and to the mosquito vector. Combination vaccines would be particularly effective in malaria control programs, as parasites that evaded the immune responses targeting sporozoites could be prevented from spreading to the mosquito vector. The OMPC carrier would also be amendable to conjugation with other malaria antigens that are targeted by antibody-mediated immunity, e.g., antigens of asexual blood stages that cause clinical disease, to provide multi-antigen vaccines that target all stages of the complex Plasmodium life cycle. The current and previous studies in immunized mice of different MHC haplotype and a non-human primate species suggests that OMPC conjugates may lead to new vaccine candidates for control and eventual eradication/elimination of malaria.

\section{ACKNOWLEDGMENTS}

We gratefully acknowledge the excellent technical assistance of Rita Altszuler and Sandra Gonzalez and we thank Leyda Cordoba for ELISA. Research at NYU was supported by NIH NIAID R01 AI45138 and R56 AI083655 to Elizabeth Nardin.

and rhesus monkeys. Vaccine 22, 2993-3003.

Herrington, D. A., Clyde, D. F., Losonsky, G., Cortesia, M., Murphy, J. R., Davis, J., et al. (1987). Safety and immunogenicity in man of a synthetic peptide malaria vaccine against Plasmodium falciparum sporozoites. Nature 328, 257-259.

Kester, K. E., Cummings, J. F., Ockenhouse, C. F., Nielsen, R., Hall, B. T., Gordon, D. M., et al. (2008). Phase $2 \mathrm{a}$ trial of 0,1 , and 3 month and 0,7 , and 28 day immunization schedules of malaria vaccine RTS, S/AS02 in malarianaive adults at the Walter Reed Army Institute of Research. Vaccine 26, 2191-2202.

Kester, K. E., Cummings, J. F., OforiAnyinam, O., Ockenhouse, C. F., Krzych, U., Moris, P., et al. (2009). Randomized, doubleblind, phase $2 \mathrm{a}$ trial of falciparum malaria vaccines RTS, S/AS01B and RTS, S/AS02A in malarianaive adults: safety, efficacy, and immunologic associates of protection. J. Infect. Dis. 200, 337-346.

Kumar, K. A., Oliveira, G. A., Edelman, R., Nardin, E., and Nussenzweig, V. (2004). Quantitative Plasmodium sporozoite neutralization assay (TSNA). J. Immunol. Methods 292, 157-164.

Langermans, J. A., Schmidt, A., Vervenne, R. A., Birkett, A. J., Calvo-Calle, J. M., Hensmann, M., et al. (2005). Effect of adjuvant on reactogenicity and long-term immunogenicity of the malaria Vaccine ICC-1132 in macaques. Vaccine 23, 4935-4943.

Latz, E., Franko, J., Golenbock, D. T., and Schreiber, J. R. (2004). Haemophilus influenzae type bouter membrane protein complex glycoconjugate vaccine induces cytokine production by engaging human toll-like receptor 2 (TLR2) and requires the presence of TLR2 for optimal immunogenicity. J. Immunol. 172, 2431-2438.

Li, H., Willingham, S. B., Ting, J. P., and Re, F. (2008). Cutting edge: 
inflammasome activation by alum and alum's adjuvant effect are mediated by NLRP3. J. Immunol. 181, 17-21.

Markwell, M. A., Haas, S. M., Bieber, L. L., and Tolbert, N. E. (1978). A modification of the Lowry procedure to simplify protein determination in membrane and lipoprotein samples. Anal. Biochem. 87, 206-210.

Massari, P., Henneke, P., Ho, Y., Latz, E., Golenbock, D. T., and Wetzler, L. M. (2002). Cutting edge: immune stimulation by neisserial porins is toll-like receptor 2 and MyD88 dependent. J. Immunol. 168, 1533-1537.

McKenzie, A., Watt, M., and Gittleson, C. (2010). ISCOMATRIX() vaccines: safety in human clinical studies. Hum. Vaccin. 6, 237-246.

Mettens, P., Dubois, P. M., Demoitie, M. A., Bayat, B., Donner, M. N., Bourguignon, P., et al. (2008). Improved $\mathrm{T}$ cell responses to Plasmodium falciparum circumsporozoite protein in mice and monkeys induced by a novel formulation of RTS, S vaccine antigen. Vaccine 26, 1072-1082.

Nahas, D. D., Palladino, J. S., Joyce, J. G., and Hepler, R. W. (2008). Amino acid analysis of peptide loading ratios in conjugate vaccines: a comparison of direct electrochemical detection and 6-aminoquinolyl-Nhydroxysuccinimidyl carbamate pre-column derivatization methods. Bioconjug. Chem. 19, 322-326.

Nardin, E. H., Oliveira, G. A., CalvoCalle, J. M., and Nussenzweig,
R. S. (1995). The use of multiple antigen peptides in the analysis and induction of protective immune responses against infectious diseases. Adv. Immunol. 60, 105-149.

Olotu, A. I., Fegan, G., and Bejon, P. (2010). Further analysis of correlates of protection from a phase 2a trial of the falciparum malaria vaccines RTS, S/AS01B and RTS, S/AS02A in malaria-naive adults. J. Infect. Dis. 201, 970-971.

Olotu, A., Moris, P., Mwacharo, J., Vekemans, J., Kimani, D., Janssens, M., et al. (2011). Circumsporozoite-specific $\mathrm{T}$ cell responses in children vaccinated with RTS, S/AS01E and protection against $P$. falciparum clinical malaria. PLoS ONE 6:e25786. doi: 10.1371/journal.pone.0025786

Othoro, C., Johnston, D., Lee, R., Soverow, J., Bystryn, J. C., and Nardin, E. (2009). Enhanced immunogenicity of Plasmodium falciparum peptide vaccines using a topical adjuvant containing a potent synthetic Toll-like receptor 7 agonist, imiquimod. Infect. Immun. 77, 739-748.

Persson, C., Oliveira, G. A., Sultan, A. A., Bhanot, P., Nussenzweig, V., and Nardin, E. (2002). Cutting edge: a new tool to evaluate human pre-erythrocytic malaria vaccines: rodent parasites bearing a hybrid Plasmodium falciparum circumsporozoite protein. J. Immunol. 169, 6681-6685.

Stewart, M. J., Nawrot, R. J., Schulman, S., and Vanderberg, J. P. (1986) Plasmodium berghei sporozoite invasion is blocked in vitro by sporozoite-immobilizing antibodies. Infect. Immun. 51, 859-864.

Sun, H. X., Xie, Y., and Ye, Y. P. (2009). ISCOMs and ISCOMATRIX. Vaccine 27, 4388-4401.

Vanderberg, J. P., and Frevert, U. (2004). Intravital microscopy demonstrating antibody-mediated immobilisation of Plasmodium berghei sporozoites injected into skin by mosquitoes. Int. J. Parasitol. 34, 991-996.

Vanderberg, J., Nussenzweig, R., and Most, H. (1969). Protective immunity produced by the injection of $\mathrm{x}$-irradiated sporozoites of Plasmodium berghei. V. In vitro effects of immune serum on sporozoites. Mil. Med. 134 1183-1190.

Wu, Y., Przysiecki, C., Flanagan, E., Bello-Irizarry, S. N., Ionescu, R., Muratova, O., et al. (2006). Sustained high-titer antibody responses induced by conjugating a malarial vaccine candidate to outer-membrane protein complex. Proc. Natl. Acad. Sci. U.S.A. 103, 18243-18248.

Young, J. F., Hockmeyer, W. T., Gross, M., Ballou, W. R., Wirtz, R. A., Trosper, J. H., et al. (1985). Expression of Plasmodium falciparum circumsporozoite proteins in Escherichia coli for potential use in a human malaria vaccine. Science 228, 958-962.

Zhou, F., Bisgard, K. M., Yusuf, H. R., Deuson, R. R., Bath, S. K., and Murphy, T. V. (2002). Impact of universal Haemophilus influenzae type $b$ vaccination starting at 2 months of age in the United States: an economic analysis. Pediatrics $110,653-661$.

Conflict of Interest Statement: Investigators at New York University School of Medicine (Elizabeth Nardin, Daniel Carapau and Robert Mitchell) report no conflict of interest. All other authors are current or past (David Kaslow, Elizabeth Ottinger) employees of Merck Research Laboratories.

Received: 11 September 2012; accepted: 06 November 2012; published online: 30 November 2012.

Citation: Przysiecki C, Lucas B, Mitchell $R$, Carapau D, Wen Z, Xu H, Wang $X-M$, Nahas D, Wu C, Hepler $R$, Ottinger E, ter Meulen J, Kaslow D, Shiver J and Nardin E (2012) Sporozoite neutralizing antibodies elicited in mice and rhesus macaques immunized with a Plasmodium falciparum repeat peptide conjugated to meningococcal outer membrane protein complex. Front. Cell. Inf. Microbio. 2:146. doi: 10.3389/fcimb. 2012.00146

Copyright (c) 2012 Przysiecki, Lucas, Mitchell, Carapau, Wen, Xu, Wang, Nahas, Wu, Hepler, Ottinger, ter Meulen, Kaslow, Shiver and Nardin. This is an open-access article distributed under the terms of the Creative Commons Attribution License, which permits use, distribution and reproduction in other forums, provided the original authors and source are credited and subject to any copyright notices concerning any third-party graphics etc. 